\title{
High-ampacity conductive polymer microfibers as fast response wear- able heaters and electromechanical actuators $\dagger$
}

\author{
Jian Zhou, ${ }^{* a}$ Matthieu Mulle, ${ }^{a}$ Yaobin Zhang, ${ }^{b}$ Xuezhu Xu, ${ }^{a}$ Er Qiang Li, ${ }^{c}$ Fei Han, ${ }^{a}$ Sigurdur T. \\ Thoroddsen $^{c}$ and Gilles Lubineau $* a$
}

\author{
Received Xth $X X X X X X X X X X 20 X X$, Accepted Xth $X X X X X X X X X 20 X X$ \\ First published on the web $X$ th $X X X X X X X X X X 200 X$ \\ DOI: $10.1039 / b 000000 x$
}

Conductive fibers with enhanced physical properties and functionalities are needed for a diversity of electronic devices. Here, we report very high performance in the thermal and mechanical response of poly(3,4-ethylenedioxythiophene)/poly(styrenesulfonate) (PEDOT/PSS) microfibers when subjected to an electrical current. These fibers were made by combining hot-drawing assisted wetspinning process with ethylene glycol doping/de-doping can work at a high current density as high as $1.8 \times 10^{4} \mathrm{~A}$ $\mathrm{cm}^{-2}$, which is comparable to that of carbon nanotube fibers. Their electrothermal response was investigated using optical sensors and verified to be as fast as $63^{\circ} \mathrm{C} \mathrm{s}^{-1}$ and is comparable with that of metallic heating elements $\left(20-50{ }^{\circ} \mathrm{C} \mathrm{s}^{-1}\right)$. We investigated the electromechanical actuation resulted from the reversible sorption/desorption of moisture controlled by electro-induced heating. Results revealed an improvement of several orders of magnitudes compared to other linear conductive polymer-based actuators in air. Specifically, the fibers we designed here have a rapid stress generation rate $\left(>40 \mathrm{MPa} \mathrm{s}^{-1}\right)$ and a wide operating frequency range (up to $40 \mathrm{~Hz}$ ). These fibers have several characteristics including fast response, low-driven voltage, good repeatability, long cycle life and high energy efficiency, favoring their use as heating elements on wearable textiles and as artificial muscles for robotics.

\section{Introduction}

Electroactive materials that convert electrical energy to thermal or mechanical energy have great potentials for many applications, including heating components for wearable textiles and artificial muscles for robots. ${ }^{1,2}$ Among these electroactive materials, conductive polymers are very promising for these types of applications because they can be easily shaped into low-voltage driven actuators and sensors. ${ }^{3-5}$ One of the most widely used conductive polymers, poly(3,4-ethylenedioxythiophene)/poly(styrenesulfonate) (PEDOT/PSS), is ideal for such applications because it is lightweight, and has good processibility, tunable electrical conductivity, suitable mechanical properties and good thermal stability. ${ }^{6-10}$

Previous works have attempted to design electroactive materials based on PEDOT/PSS. The conversion of electri-

$\dagger$ Electronic Supplementary Information (ESI) available. See DOI: 10.1039/b000000x/

${ }^{a}$ King Abdullah University of Science and Technology (KAUST), Physical Sciences and Engineering Division, COHMAS Laboratory, Thuwal 23955-6900, Saudi Arabia; E-mail:jian.zhou@kaust.edu.sa; gilles.lubineau@kaust.edu.sa Tel:+966(12)8082983;

${ }^{b}$ Shanghai Jiao Tong University, School of Mechanical Engineering, State Key Laboratory of Mechanical Systems and Vibration, Shanghai, 200240, P.R.China;

${ }^{c}$ King Abdullah University of Science and Technology (KAUST), Physical Sciences and Engineering Division, High-Speed Fluids Imaging Laboratory, Thuwal 23955-6900, Saudi Arabia. cal energy into thermal energy has been realized using PEDOT/PSS microfilms or silver nanowire/PEDOT/PSS transparent nanofilms as heaters, although the heaters had slow response times (15-80 s). ${ }^{11,12}$ Meanwhile, the conversion of electrical energy into mechanical energy has been widely investigated in PEDOT/PSS film or papers. The well-known actuation mechanism is strongly related to the highly hygroscopic nature of PEDOT/PSS. When PEDOT/PSS is subjected to an electrical current, Joule heating induces the desorption of water, which subsequently results in a volume contraction. Actuation in PEDOT/PSS-based devices thus results from an electro-thermal-mechanical coupling, a multiphysics nature that facilitates various actuation stimuli. ${ }^{11,13-16}$ For example, a (PEDOT/PSS)/elastomer bilayer actuator was developed to achieve a bending motion under multiple control stimuli, such as electrical current, heat and humidity changes. ${ }^{17}$ To date, most research on PEDOT/PSS-based electroactive materials has focused on two-dimensional films or coated papers. ${ }^{11,14,15}$ Therefore, opportunities to design PEDOT/PSS fibers or wires for specific applications, such as functional textiles, or to increase their sensitivity in general remain outstanding. In a previous study, we investigated the electromechanical actuation properties of low conductivity (PEDOT/PSS)/polyvinyl alcohol fibers, which can generate a maximum actuation stress of $11 \mathrm{MPa}$ at $8 \mathrm{~V}^{18}$ However, they feature a low response time $(80 \mathrm{~s})$, which leads to a slow stress generation rate $(0.14$ 
$\mathrm{MPa} \mathrm{s}^{-1}$ ) and a narrow operating frequency window $(<1 \mathrm{~Hz})$. Other conductive polymer fiber-based actuators have also been developed, where their actuations are controlled by oxidationreduction reactions in liquid. These materials can produce large actuation strain but have limited cyclability and the technique requires complicated counter electrode, electrolyte and device packaging. ${ }^{4,19}$

An obvious direct consequence of low efficiency in converting electrical energy to thermal or mechanical energy is an increase in power consumption. Although it has been shown that short-time application of high voltages does not harm the polymer, long term operation results in electrical failure of the materials. ${ }^{20}$ Small size microactuators should also feature enhanced response rate and be powered with coin batteries. ${ }^{3}$ In addition, increasing the conductivity of the material can improve response rate and permit the use at low voltage power sources. In our previous study, we fabricated highly conductive polymer microfibers by combining hot-drawingassisted wet-spinning process with chemical treatment (ethylene glycol doping/de-doping). ${ }^{21}$ Results showed that the performance of these fibers was superior to that of other conductive polymer fibers, with conductivity ranging from 368 to $2804 \mathrm{~S} \mathrm{~cm}^{-1}$ and Young's modulus values as high as 8.3 GPa. ${ }^{22,23}$ These improvements favored these fibers for use as actuators. For instance, their high conductivity allows them withstand high current density for long periods of time before electrical failure, and their high Young's modulus imparts good structural stability to the systems based on these fibers.

Here, we demonstrate fast electrothermal and electromechanical responses of a new generation of PEDOT/PSS fibers made by combining hot-drawing-assisted wet-spinning process and chemical treatment. By increasing the conductivity of the fibers, current density can be considerably increased a maximum current density of $1.8 \times 10^{4} \mathrm{~A} \mathrm{~cm}^{-2}$, which is two orders of magnitude of copper wires and comparable to carbon nanotube fibers, indicating their high potential for used as interconnects in a electrical circuit. Within the operating range before electrical failure, the electrothermal response was investigated systematically using fiber Bragg gratings (FBGs). The single conductive polymer fiber shows rapid electrothermal responsiveness and high reversibility at low voltages. Based on these features, the fiber bundle was demonstrated as wearable heaters on a glove. The fibers also showed remarkable electromechanical behavior induced by Joule heating and featured in fast response, long cycle life and excellent repeatability. Additionally, we show that bundles of novel fibers could be used as actuators, which can lift a load much heavier than itself. The availability of these fibers with high conductivity, high ampacity, and rapid electrothermal and electromechanical responsiveness could facilitate the development of electronic interconnects, wearable heating textiles and artificial muscles.

\section{Experimental}

\section{Materials}

The PEDOT/PSS aqueous dispersion (Clevios ${ }^{T M}$ PH1000) was purchased from HC Starck, Inc. Ethylene glycol (EG), isotropyl alcohol (IPA) and acetone were purchased from Sigma-Aldrich.

\section{Preparation of PEDOT/PSS fibers}

Fiber preparation strategies are systematically illustrated in Fig. S1†. The as-spun fiber was wet-spun from a $22 \mathrm{mg}$ $\mathrm{mL}^{-1}$ dispersion (using Clevios PH1000) followed by a vertical hot-drawing process (Fig. S1a †). Both doping and dedoping methods were used to enhance the conductivity of the fibers (Fig. S1b $\dagger$ ). Doped dispersion was prepared by adding $3 \mathrm{wt} \%$ EG in a PEDOT/PSS dispersion $\left(22 \mathrm{mg} \mathrm{ml}^{-1}\right)$. The spinning formulation (with or without EG doping) was loaded into a $5 \mathrm{~mL}$ syringe and spun into a coagulation bath though a needle with an inner diameter of $220 \mu \mathrm{m}$. The flow rate of the dispersion was controlled at $10 \mu \mathrm{L} \mathrm{min} \min ^{-1}$ by using a syringe pump. Wet fibers were pulled out from 1:1 volume ratio of acetone to IPA coagulation bath, where the volume ratio of acetone and IPA is 1 to 1 . The fibers were collected vertically onto a $50 \mathrm{~mm}$ winding spool, which gives a line speed of 2 to $4 \mathrm{~m} \mathrm{~min}^{-1}$. The temperature along the path of the fiber was set to $90^{\circ} \mathrm{C}$ by two vertically hot-plates and was monitored by a thermocouple. ${ }^{21}$ After wet-spinning, dedoping of as-spun and EG-doped fibers was performed by immersing them in a pure EG bath for $1 \mathrm{~h}$ and the fibers were then dried in air at $160{ }^{\circ} \mathrm{C}$ for $1 \mathrm{~h}$. In this study, the as-spun PEDOT/PSS fibers, EG/(PEDOT/PSS) fibers, (PEDOT/PSS)/EG fibers and EG/(PEDOT/PSS)/EG fibers represent the pristine PEDOT/PSS fibers, 3 wt $\%$ EG doped PEDOT/PSS fibers, EG de-doped PEDOT/PSS fibers and EG de-doped 3 wt $\%$ EG doped PEDOT/PSS fibers, respectively.

\section{General characterizations}

We used scanning electron microscopy (SEM) with a Quanta 600 (FEI Company) to observe the morphology of PEDOT/PSS fibers. Thermogravimetric analysis (TGA) was performed to measure the water absorbed in the fibers using a TG 209 F1 instrument (NETZSCH Company) under a nitrogen purge. Samples were heated from 25 to $800{ }^{\circ} \mathrm{C}$ at a heating rate of $10{ }^{\circ} \mathrm{C} \mathrm{min}^{-1}$.

Characterization of properties and demonstration for applications as heating elements

To assess the potential of these fibers for applications as heating elements, their electrothermal response needed to be ac- 
curately calculated. We followed a previous report based on fiber Bragg gratings (FBG) to make temperature measurements for single PEDOT/PSS fibers subjected to electrical stimulus; FBGs have been proven to be suitably efficient both experimentally and numerically. ${ }^{24}$ Measurements were performed inside a chamber to avoid environmental disturbances, and the experimental set-up is sketched in Fig. S2†. Conductive polymer fibers were prepared and fixed on a paper card. The relationships between temperature and voltage and between temperature and frequency at a certain voltage were investigated by applying electrical fields to the fiber using a 382280 DC power supply (EXETECH instruments) and an 81150 A pulse function generator (Agilent Technology). Each end of the fibers were connected with copper wires, painted with silver epoxy and sealed with an epoxy glue. The effective length of the fibers between the silver paste was $2.0 \pm 0.1$ $\mathrm{cm}$. Next, the fibers were positioned along the optical fiber containing a 5-mm long FBG and fixed with tape. The temperature of the optical fiber was monitored by an FBG (FBG1.a) connected to the first channel (CH1). An FBG reflects a part of the incident light signal that is represented by a spectrum of reflected wavelength, which peaks in correspondence with the Bragg wavelength, $\lambda_{B} .{ }^{25}$ When the FBG is only subjected to temperature changes, $\Delta T$, the peak shifts proportionally. The Bragg wavelength variation, $\Delta \lambda_{B} / \lambda_{B}$, can be expressed as ${ }^{26}$ :

$$
\Delta \lambda_{B} / \lambda_{B}=K_{T} \Delta T
$$

where, $K_{T}$, is the thermo-optic coefficient related to the temperature sensitivity of the FBG. This sensitivity was calibrated by immersing it with a thermocouple in a beaker filled with water, and the sensitivity of the FBG was determined to be 9.9 $\mathrm{pm}{ }^{\circ} \mathrm{C}^{-1} \cdot{ }^{24}$ We used 5-mm long FBGs written on SMF28e standard fibers, and the coating was removed. The Bragg wavelength of the sensor was $1530 \mathrm{~nm}$ at room temperature. The radiation/convection heat transfer was also estimated by measuring the temperature at about $700 \mu \mathrm{m}$ away from the PEDOT/PSS fibers by using another FBG (FBG2.a), which was connected to the second channel ( $\mathrm{CH} 2)$ (Fig. S2b $\dagger$ ). Note that evaluating long distance (non-contact) heat transfer is of interest for some heating applications in which the heater is not directly in contact with the system to be heated. Due to the limitation of the instrument (the data acquisition rate is 2 $\mathrm{Hz}$ ), frequencies in temperature change higher than $2 \mathrm{~Hz}$ were not measured in this study. Current flow in the fibers was monitored using a U1252B digital multimeter that captured every $1 \mathrm{~s}$ throughout the test. All tests were conducted three times in air. The FBG signal and current changes were collected through USB communication with the computer.

Knitted fabric was used to create a heatable glove, where a PEDOT/PSS fiber bundle was interlaced onto a nonconductive polyester glove. The voltage was supplied by using a 382280 DC power supply (EXETECH instruments) or a $9-\mathrm{V}$ battery. Thermal images of the glove were taken by an SC7000 thermographic camera (FLIR Systems, Inc).

\section{Characterization of properties and demonstration for ap- plication as actuators}

To test the suitability of the fibers as actuators, the following tests were conducted. Demonstration of a PEDOT/PSS fiber bundle actuator was performed under an isotonic measurement, where a load was attached to the movable end of the bundle to eliminate bulking. Displacement at the movable end was measured with a video camera, and thermal images of the fiber bundle during the actuation test were taken with an SC7000 thermographic camera. Single-fiber actuation test was performed under isometric conditions (the length of the fiber remained to be constant during the duration of the test). All tests were performed by applying a preload of $0.5 \mathrm{mN}$, which kept the fibers straight. Two types of tests are performed by applying either a constant voltage or a harmonic voltage variation with prescribed frequency. In both cases, the force generated by the fiber was monitored, where sampling rate depend on frequency. The data acquisition rate was every $100 \mathrm{~ms}$ at $0.02,0.1,0.25$ and $0.5 \mathrm{~Hz}$; every $20 \mathrm{~ms}$ for 1,2 and 5 $\mathrm{Hz}$; every $2 \mathrm{~ms}$ for 10,20 and $40 \mathrm{~Hz}$. All tests were performed at room temperature $\left(21^{\circ} \mathrm{C}\right)$ with a relative humidity of $60 \%$. The actuation stress values were determined by normalising the measured load to the fiber cross-sectional area measured before the test.

Dynamic mechanical analysis (DMA) was performed on arrays made from 15 fibers of approximately $6 \mathrm{~mm}$ in length on a Q800 instrument (TA Instruments) in tension mode. DMA measurements were performed between 25 and $120^{\circ} \mathrm{C}$, at 1 $\mathrm{Hz}$ and at a heating rate of $3{ }^{\circ} \mathrm{C} \mathrm{min}^{-1}$ in air.

\section{Results and discussion}

\section{High current density of PEDOT/PSS fibers}

Fig. 1a shows the SEM image of as-spun PEDOT/PSS fibers fabricated from a hot-drawing-assisted wet-spinning process. The length of the fibers could be several hundred meters with an average diameter of around $10 \mu \mathrm{m}$ and remarkably smooth surfaces (Fig. S4a $\dagger$ ). Before any deeper investigation into their the electrothermal and electromechanical behavior, we need to determine the maximum current density (denoted as $j_{b}$ ) that each formulation could sustain before reaching electrically induced failure. Fig. $1 \mathrm{~b}$ and Table 1 show that the $j_{b}$ is relatively small for the as-spun PEDOT/PSS fibers $\left(5.6 \times 10^{3}\right.$ $\left.\mathrm{A} \mathrm{cm}{ }^{-2}\right)$. By EG doping, $j_{b}$ increased to $7.1 \times 10^{3} \mathrm{~A} \mathrm{~cm}^{-2}$. After a combination of the EG-doping and de-doping, $j_{b}$ increased considerably (about $330 \%$ ) up to $1.8 \times 10^{4} \mathrm{~A} \mathrm{~cm}^{-2}$; this value is two orders of magnitude higher than that of cop- 

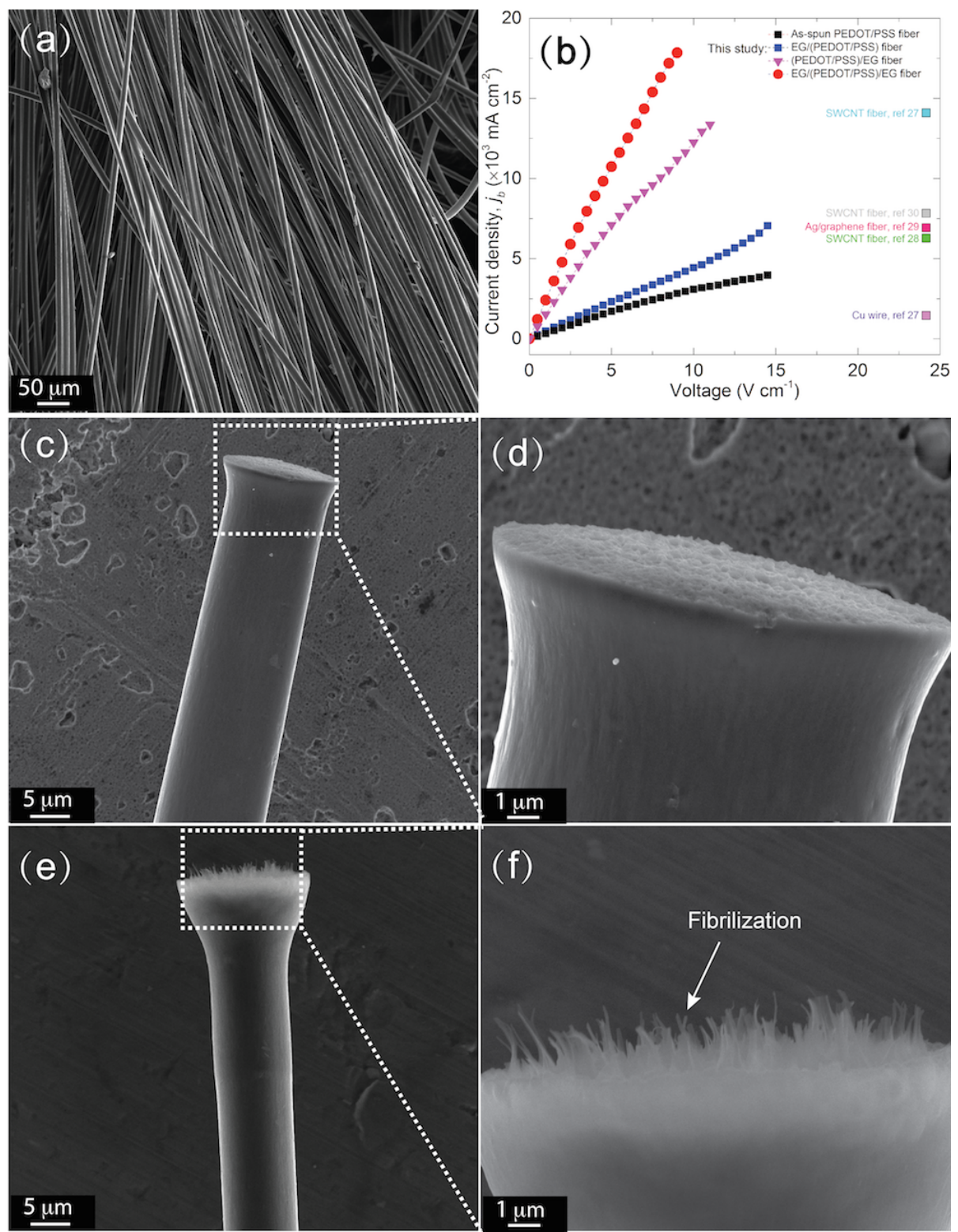

Fig. 1 Characterization of PEDOT/PSS fibers. (a) SEM image of as-spun PEDOT/PSS fibers. (b) Current density versus voltage curves of four kinds of PEDOT/PSS fibers used in this study, and the break down current densities of copper wire, carbon nanotube fiber and Ag-doped graphene fiber from literature. (c) and (d) SEM images of an as-spun PEDOT/PSS fiber after electrical failure at different magnifications. (e) and (f) SEM images of an EG/(PEDOT/PSS)/EG fiber after electric failure at different magnifications.

per wire $\left(1.6 \times 10^{2} \mathrm{~A} \mathrm{~cm}^{-2}\right)$ and even higher than that of carbon nanotube fibers and Ag-doped graphene fibers, as shown in Fig. 1b. ${ }^{27-30}$

The SEM images in Fig. 1c and d show that a slight increase in the diameter at the tip and short nodules form in the failure surface of an as-spun PEDOT/PSS fiber. Smilarly, the SEM images in Fig. 1e and $\mathrm{f}$ shows that the diameter is twice that of the original and fibrils have formed at the tip in the failure cross section of an EG/(PEDOT/PSS)/EG fiber. The failure mechanism was revealed by pure thermal heating by TG analysis in a $\mathrm{N}_{2}$ atmosphere (Fig. S4 $\dagger$ ). This technique shows that weight loss up to $120{ }^{\circ} \mathrm{C}$ can be as- 
cribed to 12 and $8 \mathrm{wt} \%$ loss of water in as-spun PEDOT/PSS fibers and EG/(PEDOT/PSS)/EG fibers, respectively. Differences in water loss indicate that PSS phases are partially removed due to EG de-doping. The first decomposition of PEDOT/PSS fibers is from $265{ }^{\circ} \mathrm{C}$ to $320{ }^{\circ} \mathrm{C}$. The weight loss of about $30 \mathrm{wt} \%$, which is attributed to the decomposition of PSS as the sulfonate groups disassociate from styrene. ${ }^{31} \mathrm{Next}$, a weight loss of about $10 \mathrm{wt} \%$ occurs between 350 and $600{ }^{\circ} \mathrm{C}$, which is caused by the rupture of the polymer backbone. ${ }^{8,31}$. It is interesting to see that both as-spun PEDOT/PSS and EG/(PEDOT/PSS)/EG fibers remain fibrous structures after heating from 25 to $800{ }^{\circ} \mathrm{C}$ (Fig. S4c $\dagger$ and $\mathrm{S} 4 \mathrm{~d} \dagger$ ). Energy dispersive $\mathrm{X}$-ray spectroscopy quantification showed that carbon to oxygen and carbon to sulfur atomic ratios increased considerably in the fiber due to degradation (Table $\mathrm{S} 1 \dagger$ ), and nanofibrils were also observed on both the surface and cross section of EG/(PEDOT/PSS)/EG fibers after degradation; However, no nanofibrils are observed for as-spun PEDOT/PSS fibers after degradation (Fig. S4c $\dagger$ ). Electrically induced failure of structures are expected to cause these types of morphological changes, and differences in changes indicated that these two polymer fibers have different microstructures.

In fact, the weakest part of the fibers is the amorphous nonconductive PSS interface that connects PEDOT/PSS grains. The decomposition temperature of PSS phases is low enough to cause an electrical current that results in over-heating followed by failure of the material (Fig. S3 $\dagger$ ). The relatively small current density of as-spun fiber can be ascribed to the presence of large amounts of PSS between PEDOT/PSS grains, in which the amorphous nature of PSS is the source of electrical failure. On the other hand, amorphous regions (PSS) of EG/(PEDOT/PSS)/EG fibers are partially removed due to EG de-doping, resulting in interconnected PEDOT grains with extremely thin layers of PSS between them. ${ }^{21,32}$ Hence, these thin layers will become fibrils from the over-heating of PSS phases induced by the electrical current. The combination of high current density and high conductivity of PEDOT/PSS fibers makes them promising candidates in the mini circuits, which need small electrical interconnects.

Table 1 Properties of PEDOT/PSS fibers for the study of electrothermal response.

\begin{tabular}{llllll}
\hline Samples & $\begin{array}{l}\text { Diameter } \\
(\mathrm{D}, \mu \mathrm{m})\end{array}$ & $\begin{array}{l}\text { Current density } \\
\left(j_{b}, \mathrm{~A} \mathrm{~cm}^{-2}\right)\end{array}$ & $\begin{array}{l}\text { Resistance } \\
(\mathrm{R}, \mathrm{k} \Omega)\end{array}$ & $\begin{array}{l}\text { Conductivity } \\
\left(\sigma, \mathrm{S} \mathrm{cm}^{-1}\right)\end{array}$ & $\begin{array}{l}\text { Young's modulus } \\
(\mathrm{E}, \mathrm{GPa})\end{array}$ \\
\hline As-spun PEDOT/PSS fiber & $9.8 \pm 1.3$ & $5.6 \times 10^{3}$ & 8.4 & 315.8 & $5.9 \pm 0.7$ \\
EG/(PEDOT/PSS) fiber & $9.7 \pm 1.4$ & $7.1 \times 10^{3}$ & 5.2 & 520.7 & $7.3 \pm 0.5$ \\
(PEDOT/PSS)EG/ fiber & $8.6 \pm 0.8$ & $1.3 \times 10^{4}$ & 2.0 & 1722.4 & $7.7 \pm 0.5$ \\
EG/(PEDOT/PSS)/EG fiber & $8.4 \pm 0.7$ & $1.8 \times 10^{4}$ & 1.1 & 3131.6 & $8.3 \pm 0.4$ \\
\hline
\end{tabular}

\section{Electrothermal response}

Chemical treatment through EG doping/de-doping not only improve the maximum current density, but also increase the conductivity of PEDOT/PSS fibers (Fig. S1 $\dagger$ ). The resistance of 2-cm-long fibers in the electrothermal response study were $8.4,5.2,2,1.1 \mathrm{k} \Omega$, corresponding to the electrical conductivities of $315.8,520.7,1722.4$ and $3131.6 \mathrm{~S} \mathrm{~cm}^{-1}$ for asspun PEDOT/PSS, EG/(PEDOT/PSS), (PEDOT/PSS)/EG and EG/(PEDOT/PSS)/EG fibers, respectively. All properties of PEDOT/PSS fibers investigated in this study are listed in Table 1.

Fig. 2a shows the changes in the temperature-time curves of the fibers when a voltage of $7 \mathrm{~V} \mathrm{~cm}^{-1}$ was applied for 25 $\mathrm{s}$. The first-order response time, $\Delta t$, of as-spun PEDOT/PSS fiber and EG/(PEDOT/PSS)/EG fiber were estimated to be 2 and $1.2 \mathrm{~s}$, respectively. The maximum heating rate estimated from Fig. 2a for the EG/(PEDOT/PSS)/EG fiber was about 63 ${ }^{\circ} \mathrm{C} \mathrm{s}^{-1}$. We also tested the thermal response of these fibers by increasing the voltage by increments of $1 \mathrm{~V} \mathrm{~cm}^{-1}$ within the operating range, as indicated in Fig. 1b. Taking the asspun PEDOT/PSS fiber and the EG/(PEDOT/PSS)/EG fiber as examples, curves of temperature variation to current were plotted with respect to time in Fig. 2b-e. Results are given for both FBGs in contact with the polymer fiber (FBG1.a) and for the one located at $700 \mu \mathrm{m}$ from the polymer fiber (FBG2.a), as show in Fig. S2b†. Each target temperature plateau at different voltage was achieved within $2.5 \mathrm{~s}$ and the first order response time, $\Delta t$, was estimated to be $1 \mathrm{~s}$. The reachable temperature measured by both FBG1.a and FBG2.a increased clearly when the resistance dropped from 8.4 to $1.1 \mathrm{k} \Omega$. To reach a target temperate of $75^{\circ} \mathrm{C}$, only $7 \mathrm{~V} \mathrm{~cm}^{-1}$ was required for EG/(PEDOT/PSS)/EG fibers, less than half of the $18 \mathrm{~V}$ $\mathrm{cm}^{-1}$ that was needed for the as-spun PEDOT/PSS fiber. Note that distance affected the change in temperature, as detected by the FBG2.a, indicating that the PEDOT/PSS fiber under an electrical current can create a temperature field nearby via radiation and convection. ${ }^{24}$ The temperature of each conductive polymer fiber is proportional to the square of the voltage applied to the fiber, proving that the coupling between electrical and thermal behaviors was generated by the Joule effect, which produces the body heat source in the PEDOT/PSS fiber (Fig. 2f). The temperature of the fiber is determined by storage of the electrical power and release of the energy through heat transfer (radiation and convection) to air. The conduction mechanism was considered to be negligible due to the loose contact of PEDOT/PSS fibers to FBGs. The temperature of the fiber, the heat flux dissipated by the fiber and the relative fraction of the radiated and convective heat flux can be extracted by a non-phenomenological model that we developed previously. ${ }^{24}$

The stable and fast heating/cooling property of the fibers was confirmed by analyzing the dynamic thermal response of the EG/(PEDOT/PSS)/EG fiber using repetitive on-off cycles with a square-wave voltage $\left(0-2.5 \mathrm{~V} \mathrm{~cm}^{-1}\right)$ at different frequencies (Fig. 2g). The amplitude of the temperature change 

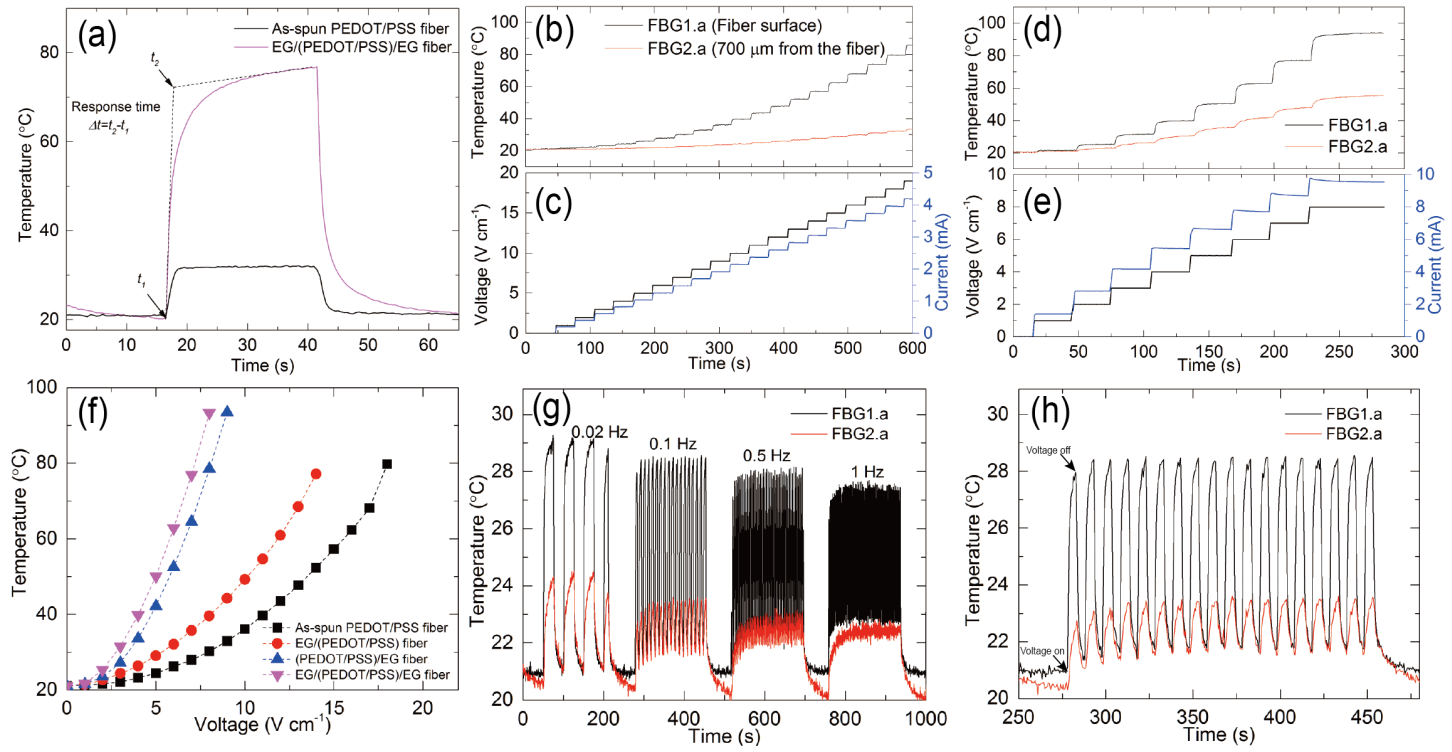

Fig. 2 Temperature sensing of single PEDOT/PSS fibers. (a) Temperature-time curves of the as-spun PEDOT/PSS fiber and EG/(PEDOT/PSS)/EG fiber at $7 \mathrm{~V} \mathrm{~cm}^{-1}$ for $25 \mathrm{~s}$. The estimation of the first order response time is shown in the figure. (b) and (c) Temperature variation and current vs. time curves of the as-spun PEDOT/PSS fiber. (d) and (e) Temperature variation and current vs. time curves of the EG/(PEDOT/PSS)/EG fiber. $1 \mathrm{~V} \mathrm{~cm}^{-1}$ increments were made for each step. (f) The dependence of temperature on voltage of four kinds of fibers measured by FBG1.a. (g) Dynamic thermal response of the EG/(PEDOT/PSS)/EG fiber measured by two FBGs at different frequencies. A square wave voltage was applied from 0 to $2.5 \mathrm{~V} \mathrm{~cm}^{-1}$ at frequencies of $0.02,0.1,0.5$ and $1 \mathrm{~Hz}$. (h) The temperature-time curves under $0.1 \mathrm{~Hz}$ of the EG/(PEDOT/PSS)/EG fiber.

Table 2 Comparisons on the performance of electrically driven heaters from the related literature. $\sigma$ is electrical conductivity, $\mathrm{R}_{S}$ is sheet resistance and $\mathrm{R}$ is the resistance.

\begin{tabular}{|c|c|c|c|c|c|c|}
\hline Heater type & $\begin{array}{l}\text { Preparation } \\
\text { method }\end{array}$ & Electrical properties & $\begin{array}{l}\text { First order } \\
\text { response }(\mathrm{s})\end{array}$ & $\begin{array}{l}\text { Max. heating } \\
\text { rate }\left({ }^{\circ} \mathrm{C} \mathrm{s}^{-1}\right)\end{array}$ & $\begin{array}{l}\text { Voltage } \\
\text { (V) }\end{array}$ & Refs. \\
\hline Tungsten wire & - & $\sigma: 1.9 \times 10^{5} \mathrm{~S} \mathrm{~cm}^{-1}$ & $0.1-0.5$ & - & - & 33 \\
\hline Copper interconnects & Lithography & $\sigma: 5.9 \times 10^{5} \mathrm{~S} \mathrm{~cm}^{-1}$ & $1-2$ & 20 & $0.3-1$ & 34 \\
\hline Gold microwire network & Sacrificial templating & $\mathrm{R}_{s}: 3.1-5.4 \Omega \mathrm{sq}^{-1}$ & $15-50$ & 50 & $2-15$ & 35 \\
\hline AgNW/PDMS & Vacuum filtration & $\mathrm{R}_{s}: 30 \Omega \mathrm{sq}^{-1}$ & 30 & 2 & $2-10$ & 36 \\
\hline AgNW/SBS & Ligand exchange & $\sigma: 3.5 \times 10^{3} \mathrm{~S} \mathrm{~cm}^{-1}$ & $10-25$ & 3 & $0.5-1$ & 37 \\
\hline AgNW/polyacrylate & Drop casting & $\mathrm{R}_{s}: 10-60 \Omega \mathrm{sq}^{-1}$ & $>15$ & 9 & $5-11$ & 38 \\
\hline $\mathrm{Ag} /$ Crackle precursor & Metal sputtering & $\mathrm{R}_{s}: 2-6 \Omega \mathrm{sq}^{-1}$ & $6-20$ & 10 & $1-5$ & 39 \\
\hline AgNW/CNT/PET film & Spray/roll-to-roll coating & $\mathrm{R}_{s}: 10-1000 \Omega \mathrm{sq}^{-1}$ & 15 & 6 & 15 & 40 \\
\hline AgNW coated cloth & Dip coating & - & 50 & 0.6 & $0.6-1.2$ & 41 \\
\hline SWCNT coated cloth & Dip coating & - & 100 & 0.3 & $8-16$ & 41 \\
\hline SWCNT functionalized fabrics & Dip coating & $\mathrm{R}: 2.5-200 \mathrm{k} \Omega$ & $30-40$ & 3 & $10-40$ & 42 \\
\hline SWCNT coated glass & Dip coating & $\mathrm{R}: 22.6-54.6 \mathrm{k} \Omega$ & $18-30$ & 1 & $10-60$ & 43 \\
\hline SWCNT coated glass or PET & Filtration and transfer & $\mathrm{R}_{s}: 0.25-3.5 \mathrm{k} \Omega \mathrm{sq}^{-1}$ & 25 & 3 & $6-12$ & 44 \\
\hline MWCNT coated glass & Pulling from CNT forest & $\mathrm{R}_{s}: 172-756 \Omega \mathrm{sq}^{-1}$ & $18-25$ & 5 & $0-40$ & 45 \\
\hline MWCNT/PDMS & Spin-coating and casting & $\mathrm{R}_{s}: 1-100 \mathrm{k} \Omega \mathrm{sq}^{-1}$ & $20-40$ & 10 & $1-100$ & 46 \\
\hline Graphene coated glass & Layer-by-layer transfer & $\mathrm{R}_{s}: 403 \Omega \mathrm{sq}^{-1}$ & $50-100$ & 2 & $6-30$ & 47 \\
\hline Graphite nanoplatelet/polyimide & Screen printing & $\mathrm{R}_{s}: 10-150 \Omega \mathrm{sq}^{-1}$ & $70-100$ & 2 & $2-14$ & 48 \\
\hline Polypyrrole coated textile & Chemical polymerization & $\mathrm{R}_{s}: 1000 \Omega \mathrm{sq}^{-1}$ & $>60$ & 1 & $5-30$ & 49 \\
\hline PEDOT/PTSA coated textile & Chemical polymerization & $\mathrm{R}_{s}: 12.8-127.9 \Omega \mathrm{sq}^{-1}$ & $>60$ & 1 & $6-24$ & 50 \\
\hline PEDOT/PSS microfilm & Casting & $\sigma: 150 \mathrm{~S} \mathrm{~cm}^{-1}$ & 15 & 3 & $2-16$ & 11 \\
\hline PEDOT nanofiber mat & Electrospinning/deposition & $\sigma: 60 \mathrm{~S} \mathrm{~cm}^{-1}$ & 15 & 3 & 10 & 51 \\
\hline $\mathrm{AgNW} /(\mathrm{PEDOT} / \mathrm{PSS}) / \mathrm{PET}$ & Blade coating & $\mathrm{R}_{s}: 3-4 \Omega \mathrm{sq}^{-1}$ & $50-80$ & 2 & $1.5-6$ & 12 \\
\hline PEDOT/PSS fibers & Wet-spinning/hot-drawing & $\sigma: 360-2804 \mathrm{~S} \mathrm{~cm}^{-1}$ & $1.2-2$ & 63 & $2-36$ & This study \\
\hline
\end{tabular}

6 | Journal Name, 2010, [vol],1-13 

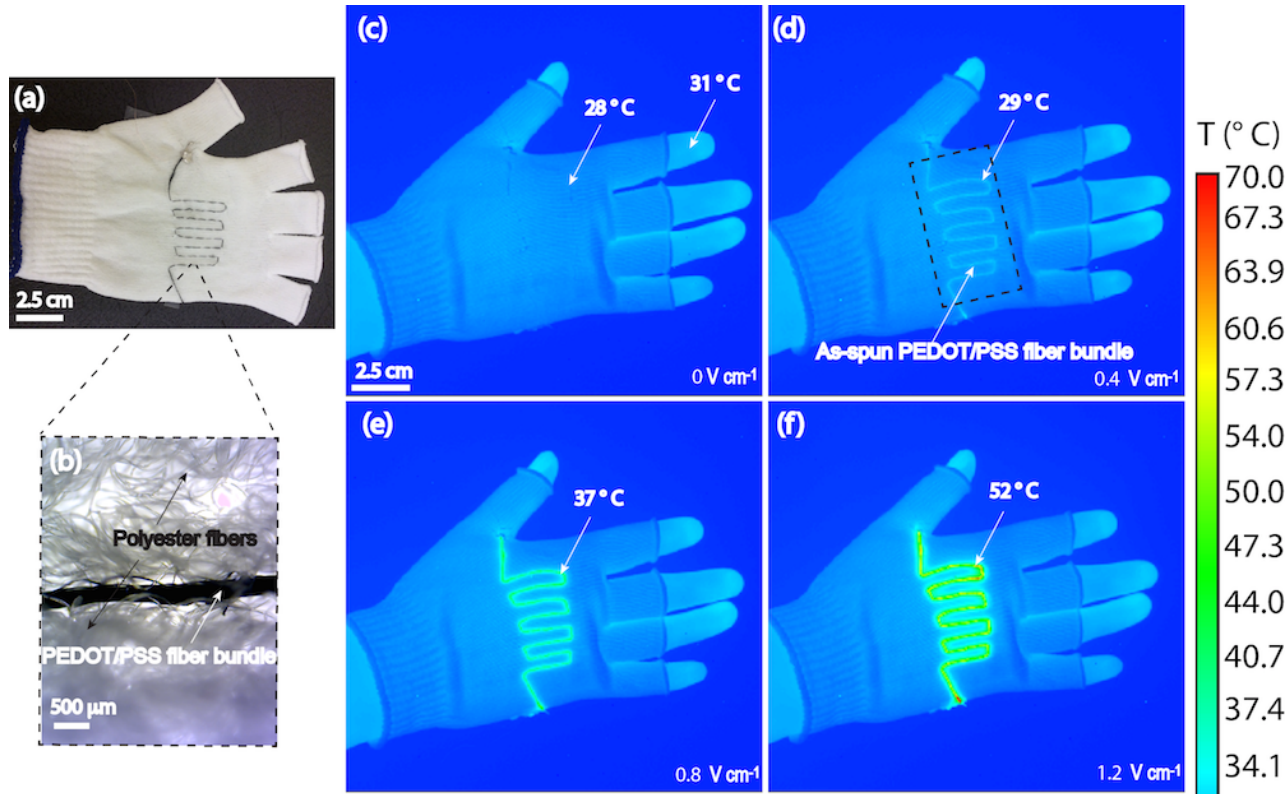

$0.8 \mathrm{~V} \mathrm{~cm}$
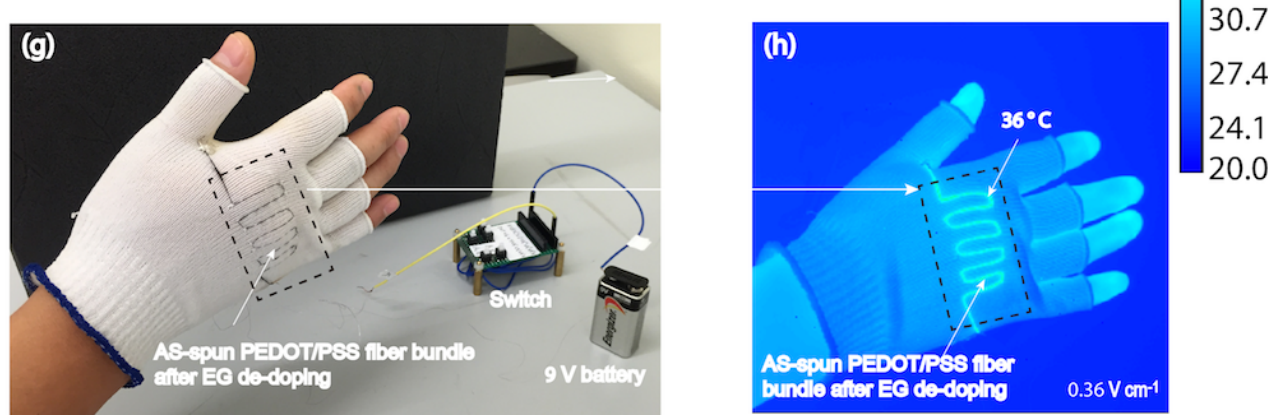

Fig. 3 A heatable glove using a PEDOT/PSS fiber bundle. (a) A PEDOT/PSS fiber bundle $(25 \mathrm{~cm}$ long) knitted on the surface of a polyester glove. (b) Optical image of the PEDOT/PSS fiber bundle in polyester glove. (c)-(f) Thermal images showing temperatures of the as-spun PEDOT/PSS fiber bundle on a polyester glove at $0,0.4,0.8$ and $1.2 \mathrm{~V} \mathrm{~cm}^{-1}$, respectively. (g) A photo of an assembled circuit with a heatable glove using a 9-V battery. For comparison, the fiber bundle is the as-spun fiber bundle used in (c) to (f) after EG de-doping. (h) The corresponding thermal image in $(\mathrm{g})$ powered by a $9-\mathrm{V}$ battery.

stayed nearly constant at each frequency, indicating that the thermal response is stable and repeatable for long-term use; however, from one frequency to another, the temperature variation differs, showing that higher frequency cause less temperature variation. This indicates that either maximum Joule heat was not generated or that its transmission to the temperature sensor was not completed before the start of the next cycle. In detail, when the curve at $0.1 \mathrm{~Hz}$ was enlarged, as shown in Fig. $2 \mathrm{~h}$, it clearly shows a reversible heating/cooling process. The first order response time during both heating and cooling was about $1 \mathrm{~s}$. The fast cooling rate of the PEDOT/PSS fiber was associated with the small diameter of the fiber and fast water absorption to reduce the temperature of the fiber. The water absorption will start with the fixation of $\mathrm{H}_{2} \mathrm{O}$ molecules on the highly hygroscopic $\mathrm{SO}_{3} \mathrm{H}$ groups in PSS, which will lead to expansion of the material. Then the weakened hydrogen bonds in $\mathrm{SO}_{3} \mathrm{H}$ will react with water via reversible reactions during the cooling/heating processes below. ${ }^{6,52,53}$ The superior dynamic thermal response of the fiber is extremely crucial for fast thermal response applications, which need reliable repeatability.

$$
\begin{aligned}
& \mathrm{H}_{2} \mathrm{O}+\mathrm{PSS}\left(\mathrm{HSO}_{3}\right) \stackrel{\text { Cooling }}{\longrightarrow} \mathrm{H}_{3} \mathrm{O}^{+} \mathrm{PSS}\left(\mathrm{SO}_{3}\right)^{-} \\
& \mathrm{H}_{3} \mathrm{O}^{+} \mathrm{PSS}\left(\mathrm{SO}_{3}\right)^{-} \stackrel{\text { Heating }}{\longrightarrow} \mathrm{H}_{2} \mathrm{O}+\mathrm{PSS}\left(\mathrm{HSO}_{3}\right)
\end{aligned}
$$


Table 2 compares the performance of various electrically driven heaters prepared by different methods. The first-order response time of PEDOT/PSS fibers is comparable with tungsten wires or copper interconnects, which need several hundred mini-seconds to several seconds. ${ }^{33,34}$ Moreover, these fibers have the fastest response rate $\left(63{ }^{\circ} \mathrm{C} \mathrm{s}^{-1}\right)$ compared with other types of heaters. Nanomaterial-based heaters, such as silver nanowires (AgNWs), carbon nanotubes (CNTs) and graphene, generally need a long response time for heating because substrates hinder the measured heating rate as compared to a free-standing arrangement. Some other PEDOT based heaters, such as PEDOT/PSS film and PEDOT nanofiber mat, have a response time several times longer than our PEDOT/PSS fibers due to their low conductivities. ${ }^{11,51}$ The fast response of PEDOT/PSS fibers is ascribed to the small diameter and a direct measurement without any substrate attached to the fibers. To summarize, the merit of PEDOT/PSS fibers as heaters lies in (1) very fast response which is comparable with metal wires; (2) low density, high conductivity, high flexibility, stretchability and better tolerance to frequent bending and contact as compared to carbon fibers and metallic wires ${ }^{54}$; and (3) good spinnability for directly co-spinning with nonconductive polyester fibers from different nozzles, which can be easily twisted and woven into textiles for the application of wearable heaters.

As we know that the temperature range required for wearable applications is much lower than the maximum temperature generated by the fiber $\left(90{ }^{\circ} \mathrm{C}\right)$ and the initial thermal degradation temperature of the fiber $\left(265^{\circ} \mathrm{C}\right)$, the thermal stability of the PEDOT/PSS fiber is estimated to be appropriate for wearable heating textiles. Fig. 3 demonstrates the application of PEDOT/PSS fibers as heating elements on a glove. A textile-based electrode was fabricated by knitting a PEDOT/PSS fiber bundle $(25 \mathrm{~cm}$ long) onto the surface of a polyester glove, as show in Fig. 3a and b. Fibers were adequately strong to avoid damage during knitting or from repeated exposure to tensile and bending strains on the hand. This is due to the excellent stretchability of PEDOT/PSS fibers (16 to $21 \%$ ) compared with metallic wires or carbon nanotube fibers ( 1 to $8 \%) .^{21,28,55}$ The representative thermal images that taken at $0,0.4,0.8$ and $1.2 \mathrm{~V} \mathrm{~cm}^{-1}$ at steady state show a clear temperature increase from 28 to $52{ }^{\circ} \mathrm{C}$ for the as-spun PEDOT/PSS fiber bundle (Fig. $3 \mathrm{c}$ to f). The temperature distribution of the coiled fiber bundle at each applied voltage was predominately homogeneous. The bundle produces heat not only along the paths where the fiber bundle extend but also into the spaces between adjacent segments, especially at high voltages. A heat field generated by the fiber bundle at $1.2 \mathrm{~V} \mathrm{~cm}^{-1}$ becomes apparent, further proving that the non-contact heating mechanism (radiation and convection) is integral to the heat flux in the nearby environment. To approach the practical use of these fibers as heating elements, the as-spun PEDOT/PSS fiber bundle used in Fig. 3g was EG de-doped to enhance electrical conductivity. ${ }^{21}$ Now, the fiber bundle on the glove can be powered by a $9-\mathrm{V}$ battery (corresponding to an electrical field of $0.36 \mathrm{~V} \mathrm{~cm}^{-1}$ ) and can reach a maximum temperature of $36{ }^{\circ} \mathrm{C}$ (Fig. $3 \mathrm{~g}$ and $\mathrm{h}$ ), which is a comfortable temperature range for hands (between 33 and $38{ }^{\circ} \mathrm{C}$ ). ${ }^{41,54}$ Smaller power sources, such as coin batteries, could also be used, but the location of the electrodes, the conductivity and the arrangement of the fiber bundle on the glove would need to be engineered.

\section{Electromechanical response}

We applied voltages to a similar fiber bundle as that used in the heatable gloves and found that it displayed linear electromechanical motion. The preliminary actuation performance of the fibers presented as a bundle actuator containing 118 fibers with $14 \mathrm{~cm}$ in length under isotonic conditions, as show in Fig. $4 \mathrm{a}$ and $\mathrm{b}$. Applying voltage to the fiber bundle enables it to lift up a $0.45 \mathrm{~g}$ load, which is 150 times of the fiber bundle $(3 \mathrm{mg})$. Using a video camera, we measured the displacement, $\Delta L$, and found that it took about $6 \mathrm{~s}$ to reach a maximum displacement of $530 \mu \mathrm{m}$ with a first order response of $2 \mathrm{~s}$ when applying a voltage of $1.14 \mathrm{~V} \mathrm{~cm}^{-1}$ (Fig. 4c). This value corresponds to an actuation strain of $0.4 \%$, which is appropriate for use as heating elements on gloves because by switching the voltage on and off, would not be noticeable to the wearer; however, this would be a limitation especially for applications that need large actuation strokes. Here, we show that aligning polymer chains to increase electronic conductivity and Young's modulus leads to low power consumption, long cycle life and good repeatability. The lower actuation strains in the fiber compared with films could be attributed to the preferential orientation of PEDOT chains along the fibers direction. ${ }^{11,21,32}$ The actuation strain can be increased by amplifiers such as level systems or by improving the relative humidity around the actuator. ${ }^{11,56}$ In addition, we took the thermal images of the fiber bundle at different voltages, and as show in Fig. 4d, tensile actuation is correlated with and depends on the temperature of the fiber bundle. The evolution of displacement with voltage is plotted together with the temperature of the fiber bundle (Fig. 4e); the displacement clearly increased with temperature until reaching saturation after $40{ }^{\circ} \mathrm{C}$.

By measuring the tensile actuation of single fibers, we learned more about what affects their actuation performance (Fig. 5a). A 2-cm fiber weighing $2.2 \mu \mathrm{g}$ was clamped and preloaded with a force of $0.5 \mathrm{mN}$ to keep it tight and straight. Actuation stress was then measured as the voltage, $V$, was increased while the extension was held constant. Actuation stress evolved in three regimes as the applied voltage increased for both as-spun PEDOT/PSS and EG/(PEDOT/PSS)/EG fibers, as shown in Fig. 5b. In the first regime $\left(0<V<V_{p}\right)$, actuation stress increases with 

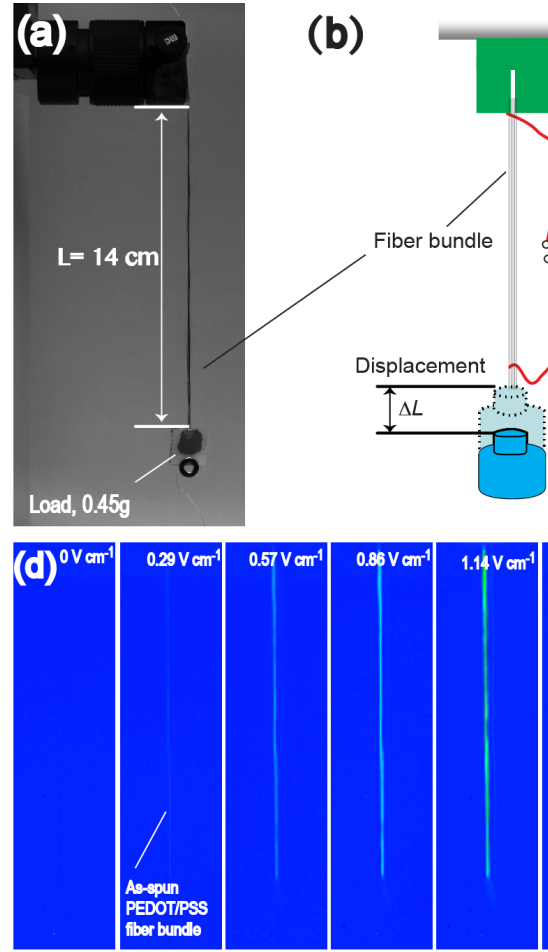

(b)

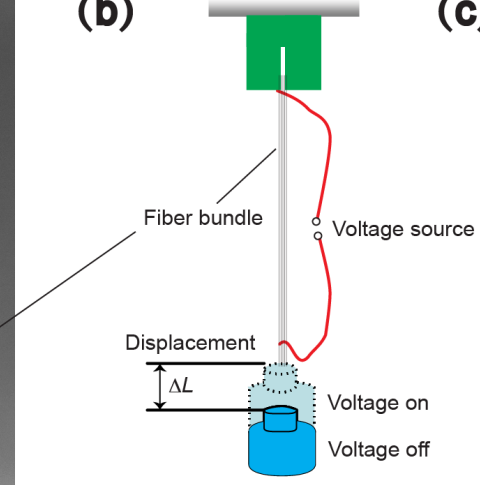

(c)

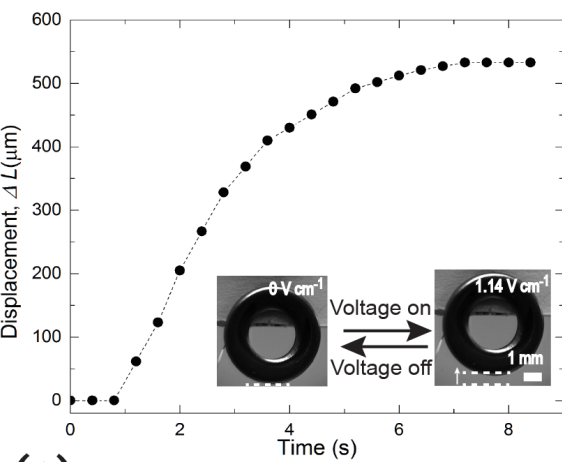

(e)

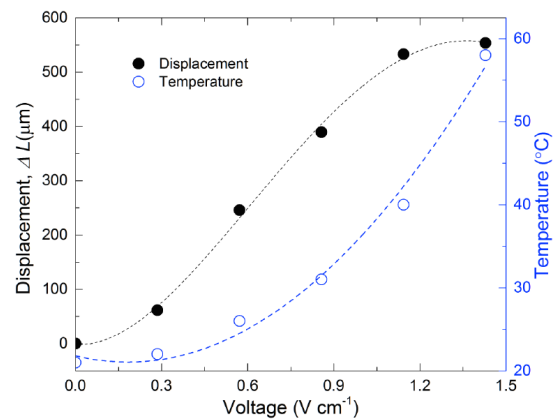

Fig. 4 Performance of the as-spun PEDOT/PSS fiber bundle actuator under isotonic conditions. (a) Photograph of a 14-cm-long as-spun PEDOT/PSS fiber bundle ( $3 \mathrm{mg}$ ) carrying a $0.45 \mathrm{~g}$ load on its movable end. (b) Illustration of the set-up shows the motion of the actuator by switching the voltage on and off. (c) The evolution of displacement with time at $1.14 \mathrm{~V} \mathrm{~cm}^{-1}$. Inset images show the position change of the load by switching the voltage on and off. (d) The corresponding thermal images of the fiber bundle in (a) at different voltages. (e) Readings from video and thermal camera give the displacement and temperature of the fiber bundle as functions of the applied voltage, respectively.

voltage such that the maximum actuation stress amplitudes, $\Delta \sigma$, at peak voltage, $V_{p}$, were $14 \mathrm{MPa}\left(V_{p}=6 \mathrm{~V} \mathrm{~cm}^{-1}\right)$ and $22 \mathrm{MPa}\left(V_{p}=2.5 \mathrm{~V} \mathrm{~cm}^{-1}\right)$ for as-spun PEDOT/PSS and EG/(PEDOT/PSS)/EG fibers, respectively. These values are close to those generated by PEDOT/PSS films or papers ${ }^{11,13}$ and are also comparable with the performance of polypyrrole-based actuators $(27 \mathrm{MPa})$ driven by moisture gradients. ${ }^{57}$ Note that the peak temperature, $T_{p}$, of the fiber at the maximum $\Delta \sigma$ for both fibers was about $30{ }^{\circ} \mathrm{C}$. In the second regime $\left(V_{p}<V<V_{t}\right)$, the mechanical response of the fibers lies in a state of equilibrium. The $\Delta \sigma$ remains almost constant when the voltage is increased. We propose that at relatively higher voltage levels, the fibers may start to soften and expand. In the third regime $\left(V>V_{t}\right)$, the temperature increases over $40{ }^{\circ} \mathrm{C}$ and $60^{\circ} \mathrm{C}$ for as-spun PEDOT/PSS fiber and EG/(PEDOT/PSS)/EG fiber, respectively (Fig. 2f). The actuation stress drops when voltages are higher than $V_{t}$ (11 and $6 \mathrm{~V} \mathrm{~cm}^{-1}$ for as-spun PEDOT/PSS and EG/(PEDOT/PSS)/EG fibers, respectively). We ascribe $\mathrm{V}_{t}$ and $T_{t}$ as the turning voltage and temperature for actuation, respectively. DMA analysis was performed to explain the evolution of $\Delta \sigma$ with temperature. We found that at first the storage modulus increased with temperature up to $T_{p}$, which was due to the desorption of water from the fibers, but then it decreased due to the softening and expansion of amorphous PSS phases at higher temperatures (Fig. 5c). As a result, reduced actuation stress was caused by softening of the amorphous PSS phase in the fiber at higher temperatures $\left(T>T_{t}\right)$, and the thermal expansion of the fibers is compensation for the contraction of the fibers induced by the electrical current. Our result agrees with the results of PEDOT/PSS film or paper actuation at higher temperatures, where the actuation stress reduces due to thermal expansion of PEDOT/PSS. ${ }^{11,13}$

Knowing that the actuation stress can be generated and maximized in the first regime $\left(0<V<V_{p}\right)$, we applied a cyclic current loading to the fiber to investigate the repeatability of the actuator in this regime. The actuation stress, voltage and current of the fibers at $0.02 \mathrm{~Hz}$ and a square wave voltage of $2.5 \mathrm{~V} \mathrm{~cm}^{-1}$ are shown in Fig. 6a-d. Using EG/(PEDOT/PSS)/EG fibers as an example, when the cur- 
(a)

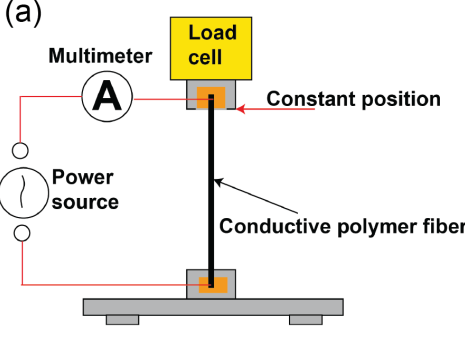

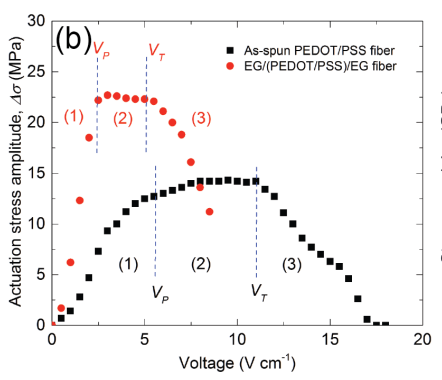

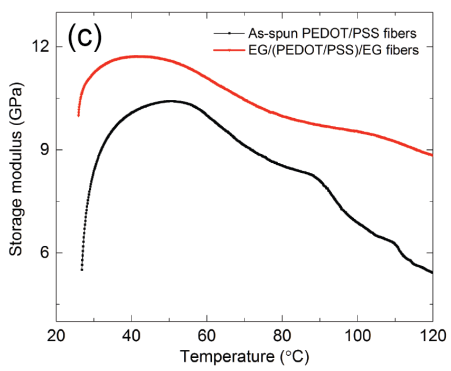

Fig. 5 (a) The set-up for isometric measurement of fibers. (b) Actuation stress amplitude to voltage profiles of the as-spun PEDOT/PSS and EG/(PEDOT/PSS)/EG fibers. (c) Dynamic mechanical behavior of as-spun PEDOT/PSS fibers and EG/(PEDOT/PSS)/EG fibers.

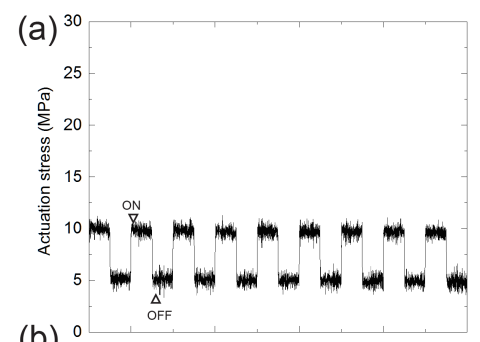

(b)

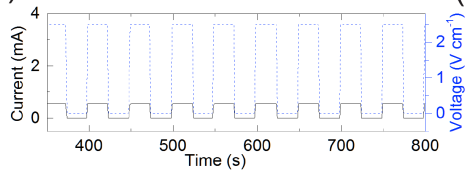

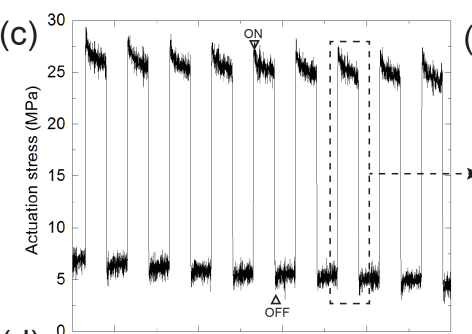

(d)

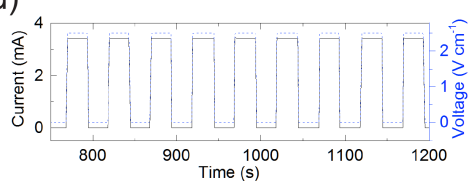

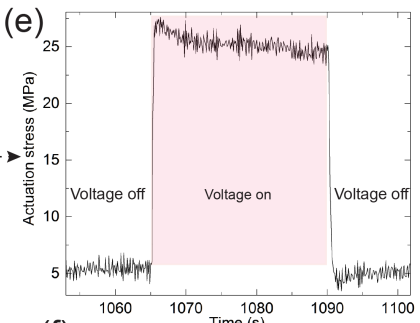

(f)

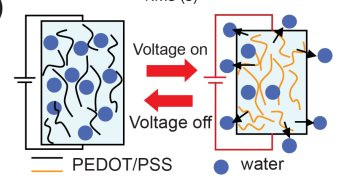

Fig. 6 Low frequency actuation of single PEDOT/PSS fibers at $0.02 \mathrm{~Hz}$. (a) and (b) Tensile actuation of the as-spun PEDOT/PSS fiber under the applied square wave voltage $\left(0-2.5 \mathrm{~V} \mathrm{~cm}^{-1}\right)$. (c) and (d) Tensile actuation of the EG/(PEDOT/PSS)/EG fiber under the applied square wave voltage $\left(0-2.5 \mathrm{~V} \mathrm{~cm}^{-1}\right)$. (e) The enlarged figure in the dash box of (d). (f) Illustration graph of actuation mechanism.

rent passing through the fiber is $3.5 \mathrm{~mA}$ and the temperature is raised from 21 to $29{ }^{\circ} \mathrm{C}$ (Fig. 2f). Under the isometric condition, the fiber charges the actuation force as elastic energy and then releases this energy by contracting reversibly from maximum tension to near zero. Fig. 6e, the response time is estimated about $0.5 \mathrm{~s}$. The fiber shows a repeatable generation of the actuation stress with fast rates of $40 \mathrm{MPa}$ $\mathrm{s}^{-1}$, a value that is comparable to the peak capacity of natural and other artificial muscles (30 $\left.\mathrm{MPa} \mathrm{s}^{-1}\right) ;{ }^{20,58}$ and an actuation mechanism similar to that of PEDOT/PSS films or papers in humid air. ${ }^{11,13}$ When an electrical field is applied to the sample, electrical energy is converted to thermal energy, causing temperature to increase on the fiber (Fig. 4d). Then the water vapor absorbed by the fiber desorped to a certain level due to Joule heating, the volume of the fiber changed (Fig. 6f). Superior and reversible electrothermal heating of the PEDOT/PSS fibers, caused a reversible electro-induced actuation simplifying the actuation mechanism: an electro-thermalmechanical energy transfer in PEDOT/PSS fibers. The overall phenomenology has been well validated for a wide range of conductive polymers, including PEDOT/PSS and polypyrrole. For both, experiments have been performed either under vacuum or with various relative humidity levels and the key role of water sorption/desorption has been confirmed in the actuation process. ${ }^{11,13,59}$

Square-wave voltages at different frequencies were applied to further investigate the high frequency performance of PEDOT/PSS fiber actuators. Inset curves in Fig. 7a show that the actuation amplitude remains almost constant below $1 \mathrm{~Hz}$. As actuation frequency increased, we observed a reduced actuation stress amplitude after $1 \mathrm{~Hz}$ between the on and off states. We suggest that neither actuated or relaxed states achieved stability because duration of the step voltage was insufficient (Fig. 7a and b). Actuation was appreciable up to $40 \mathrm{~Hz}$ for EG/(PEDOT/PSS)/EG fibers, and the long-term reliability of actuator performance was evaluated by repetitive cycling of this fiber actuator up to 10,000 cycles at $1 \mathrm{~Hz}$. No obvious decline in the actuation amplitude presented with more than 10,000 cycles (Fig. 7c and Fig. S5†), which is likely because the fiber actuator worked in the elastic region and because 

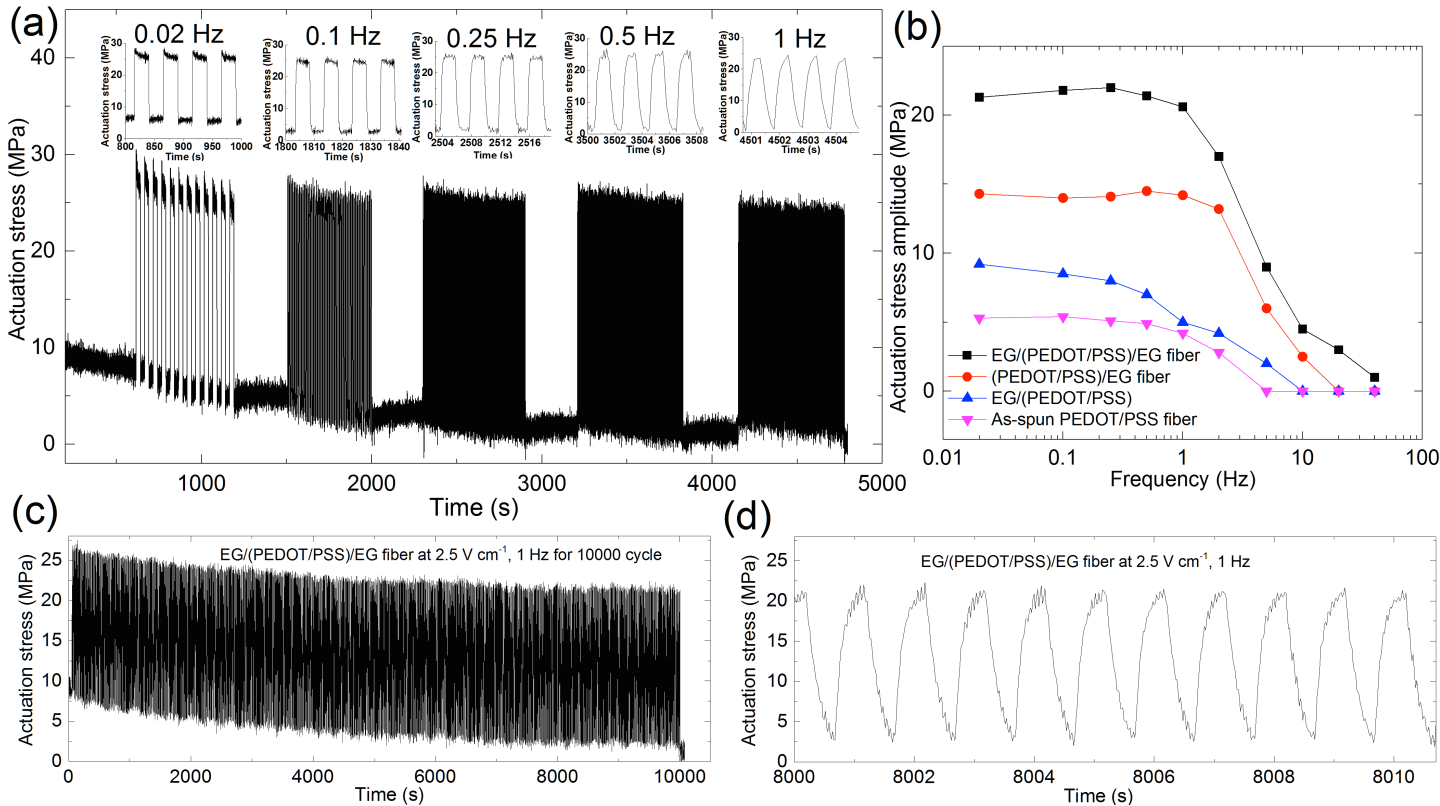

(d)

Fig. 7 Frequency-dependent actuation of PEDOT/PSS fibers. (a) Tensile actuation of the EG/(PEDOT/PSS)/EG fiber at different frequencies $(0.02,0.1,0.25,0.5$ and $1 \mathrm{~Hz})$ at a square wave voltage $\left(0-2.5 \mathrm{~V} \mathrm{~cm}^{-1}\right)$. Inset curves show details of the actuation at different frequencies. (b) Actuation stress amplitude as a function of driven frequency at a square-wave voltage $\left(0-2.5 \mathrm{~V} \mathrm{~cm}^{-1}\right)$. (c)Tensile actuation of the EG/(PEDOT/PSS)/EG fiber under the applied $1 \mathrm{~Hz}$ square-wave voltage $\left(0-2.5 \mathrm{~V} \mathrm{~cm}^{-1}\right)$ for 10,000 cycles. (d) Detailed information on the tensile actuation given in (c).

of the superior Young's modulus over PEDOT/PSS films. ${ }^{11}$ The performance of conductive polymer-based linear actuators from the literature is summarized and compared with this study in Table 3. Though the PEDOT/PSS have been shown before in the film or fiber structure as actuators, the novelty of the current work lines in clearly understanding the electrothermal and electromechanical response of a pure single conductive polymer fiber. To summarise, our fiber actuators have several merits including the following: (1) they are capable of working directly in air at a low-driven voltage; (2) continuous fiber can be readily bundled for use as large force linear actuators. Assembly of these fibers in air is much easier than other conductive polymer film actuators; (3) they have a fast response rate (up to $40 \mathrm{MPa} \mathrm{s}^{-1}$ ); (4) wide frequency operating window (0.02 to $40 \mathrm{~Hz}$ ); and (5) excellent repeatability and long cycle life of the actuator due to their improved Young's modulus compared with films.

\section{Conclusions}

In summary, we systematically studied the current density, electrothermal and electromechanical responses of highly conductive PEDOT/PSS fibers. We construct these fibers by a combination of thermomechanical (hot-drawing-assisted wet- spinning) and chemical treatment (EG doping/de-doping). We found that high-performance PEDOT/PSS fibers can carry high current density that is comparable with carbon nanotube fibers, making them promising candidates for use as interconnects in circuits. These fibers could also be used as heating elements in wearable textiles because they enable rapid heating at low operation voltages and show excellent heating repeatability. Moreover, The unique electromechanical response of PEDOT/PSS fibers surpasses other conductive polymer based actuators working in air. They feature with low-driven voltage, fast response time $(<0.5 s)$, a wide frequency window (up to $40 \mathrm{~Hz}$ ), excellent repeatability (10,000 cycles) and controllability in air. We demonstrated that a PEDOT/PSS fiber bundle can be used as a glove heater powered by a $9-\mathrm{V}$ battery. The fiber bundle can also be used as a linear actuator to lift a load that is 150 times of its own weight. Our results provide the basis bear the potential of these fibers to be implemented in wearable heating textiles and in microelectromechanical systems that need actuators.

\section{Acknowledgments}

We thank Mr. Isaac Aguilar Ventura for his help with the actuation measurement setup. Research reported in this publica- 
Table 3 Comparisons of the performance of linear, conductive polymer actuators that work in air.

\begin{tabular}{|c|c|c|c|c|c|c|}
\hline Materials & $\begin{array}{l}\text { Driven voltage } \\
\text { (V) }\end{array}$ & $\begin{array}{l}\text { Maximum actuation stress } \\
\text { (MPa) }\end{array}$ & $\begin{array}{l}\text { Maximum actuation strain } \\
(\%)\end{array}$ & $\begin{array}{l}\text { Response time } \\
\text { (s) }\end{array}$ & $\begin{array}{l}\text { Maximum frequency } \\
(\mathrm{Hz})\end{array}$ & References \\
\hline $\mathrm{PPy}\left(\mathrm{BF}_{4}\right)_{0.33}\left(\mathrm{H}_{2} \mathrm{O}\right)_{0.25}$ film & $0-3$ & 8.9 & 1 & 50 & - & 56,5 \\
\hline PEDOT/PSS film & $0-10$ & 17 & $2.4-4.5$ & 20 & - & 11 \\
\hline PEDOT semi-IPN hollow fiber & $0-1$ & $<1$ & 3 & 80 & - & 19 \\
\hline PEDOT/PSS/PVA blended fiber & $0-8$ & 11 & 0.12 & 50 & 1 & 18 \\
\hline As-spun PEDOT/PSS fiber & $0-20$ & 13 & $\sim 0.4$ & 0.5 & 2 & This study \\
\hline EG/(PEDOT/PSS) fiber & $0-16$ & 16 & $\sim 0.4$ & 0.5 & 5 & This study \\
\hline (PEDOT/PSS)EG/ fiber & $0-8$ & 19 & $\sim 0.4$ & 0.5 & 10 & This study \\
\hline EG/(PEDOT/PSS)/EG fiber & $0-5$ & 22 & $\sim 0.4$ & 0.5 & 40 & This study \\
\hline
\end{tabular}

tion was supported by baseline funding from King Abdullah University of Science and Technology (KAUST). The authors are grateful to KAUST for its continuous support.

\section{References}

1 T. Mirfakhrai, J. D. W. Madden and R. H. Baughman, Mater. Today., 2007, 10, 30-38.

2 M. A. C. Stuart, W. T. S. Huck, J. Genzer, M. Muller, C. Ober, M. Stamm, G. B. Sukhorukov, I. Szleifer, V. V. Tsukruk, M. Urban, F. Winnik, S. Zauscher, I. Luzinov and S. Minko, Nat. Mater., 2010, 9, 101-113.

3 E. Smela, Adv. Mater., 2003, 15, 481-494.

4 W. Lu, E. Smela, P. Adams, G. Zuccarello and B. R. Mattes, Chem. Mater., 2004, 16, 1615-1621.

5 H. Okuzaki and K. Funasaka, Macromolecules, 2000, 33, 8307-8311.

6 J. Zhou, D. Anjum, L. Chen, X. Xu, I. Ventura, L. Jiang and G. Lubineau, J. Mater. Chem. C., 2014, 2, 9903-9910.

7 J. Zhou and G. Lubineau, ACS. Appl. Mater. Interfaces., 2013, 5, 6189-6200.

8 J. Zhou, I. Ventura and G. Lubineau, Ind. Eng. Chem. Res., 2014, 53, 3539-3549.

9 I. Aguilar Ventura, J. Zhou and G. Lubineau, Composite. Sci. Technology., 2015, 117, 342-350.

10 I. Aguilar Ventura, J. Zhou and G. Lubineau, Nanoscale Res. Lett., 2015, 10, 485.

11 H. Okuzaki, H. Suzuki and T. Ito, J. Phys. Chem. B., 2009, 113, 11378-11383.

12 S. L. Ji, W. W. He, K. Wang, Y. X. Ran and C. H. Ye, Small, 2014, 10, 4951-4960.

13 J. Zhou, T. Fukawa, H. Shirai and M. Kimura, Macromolecular. Mater. Eng., 2010, 295, 671-675.

14 J. Zhou and M. Kimura, Sen-i. Gakkaishi., 2011, 67, 125131.

15 J. Zhou, T. Fukawa and M. Kimura, Polym. J., 2011, 43, 849-854.

16 J. Zhou, Q. Gao, T. Fukawa, H. Shirai and M. Kimura, Nanotechnology, 2011, 22, year.
17 S. Taccola, F. Greco, E. Sinibaldi, A. Mondini, B. Mazzolai and V. Mattoli, Adv. Mater., 2015, 27, 1668-1675.

18 H. Miura, Y. Fukuyama, T. Sunda, B. Lin, J. Zhou, J. Takizawa, A. Ohmori and M. Kimura, Adv. Eng. Mater., 2014, 16, 550-555.

19 C. Plesse, F. Vidal, D. Teyssie and C. Chevrot, Chem. Commun., 2010, 46, 2910-2912.

20 M. D. Lima, N. Li, M. J. de Andrade, S. L. Fang, J. Oh, G. M. Spinks, M. E. Kozlov, C. S. Haines, D. Suh, J. Foroughi, S. J. Kim, Y. S. Chen, T. Ware, M. K. Shin, L. D. Machado, A. F. Fonseca, J. D. W. Madden, W. E. Voit, D. S. Galvao and R. H. Baughman, Science, 2012, 338, 928-932.

21 J. Zhou, E. Q. Li, R. Li, X. Xu, I. Aguilar Ventura, A. Moussawi, D. Anjum, M. N. Hedhili, D. Smilgies, G. Lubineau and S. T. Thoroddsen, J. Mater. Chem. C., 2015, 3, 2528-2538.

22 H. Okuzaki, Y. Harashina and H. Yan, Europ. Polym. J., 2009, 45, 256-261.

23 R. Jalili, J. M. Razal, P. C. Innis and G. G. Wallace, $A d v$. Funct. Mat., 2011, 21, 3363-3370.

24 J. Zhou, Y. Zhang, M. Mulle and G. Lubineau, Meas. Sci. Technol., 2015, 26, 085003.

25 K. O. Hill and G. Meltz, J. Lightwave. Technol., 1997, 15, 1263-1276.

26 Y. J. Rao, Opt. Laser. Eng., 1999, 31, 297-324.

27 X. Wang, N. Behabtu, C. C. Young, D. E. Tsentalovich, M. Pasquali and J. Kono, Adv. Funct. Mater., 2014, 24, 3241-3249.

28 N. Behabtu, C. C. Young, D. E. Tsentalovich, O. Kleinerman, X. Wang, A. W. K. Ma, E. A. Bengio, R. F. ter Waarbeek, J. J. de Jong, R. E. Hoogerwerf, S. B. Fairchild, J. B. Ferguson, B. Maruyama, J. Kono, Y. Talmon, Y. Cohen, M. J. Otto and M. Pasquali, Science, 2013, 339, 182-186.

29 Z. Xu, Z. Liu, H. Y. Sun and C. Gao, Adv. Mater., 2013, 25, 3249-3253.

30 F. C. Meng, X. H. Zhang, R. Li, J. N. Zhao, X. H. Xuan, X. H. Wang, J. Y. Zou and Q. W. Li, Adv. Mater., 2014, 26, 2480-2485.

31 D. Antiohos, G. Folkes, P. Sherrell, S. Ashraf, G. Wallace, 
P. Aitchison, A. Harris, J. Chen and A. Minett, J Mater Chem, 2011, 21, 15987-15994.

32 J. Zhou, D. H. Anjum, G. Lubineau, E. Q. Li and S. T. Thoroddsen, Macromolecules, 2015, 48, 5688-5696.

33 P. Liu, L. Liu, Y. Wei, K. Liu, Z. Chen, K. L. Jiang, Q. Q. Li and S. S. Fan, Adv. Mater., 2009, 21, 3563-3566.

34 A. H. Hussain, E. B. Lizardo, G. A. T. Sevilla, J. M. Nassar and M. M. Hussain, Adv. Healthcare. Mater., 2015, 4, 665-673.

35 K. D. M. Rao and G. U. Kulkarni, Nanoscale, 2014, 6, $5645-5651$.

36 S. Hong, H. Lee, J. Lee, J. Kwon, S. Han, Y. D. Suh, H. Cho, J. Shin, J. Yeo and S. H. Ko, Adv. Mater., 2015, 27, 4744-4751.

37 S. Choi, J. Park, W. Hyun, J. Kim, J. Kim, Y. B. Lee, C. Song, H. J. Hwang, J. H. Kim, T. Hyeon and D. H. Kim, ACS. Nano., 2015, 9, 6626-6633.

38 J. P. Li, J. J. Liang, X. Jian, W. Hu, J. Li and Q. B. Pei, Macromol. Mater. Eng., 2014, 299, 1403-1409.

39 R. Gupta, K. D. M. Rao, K. Srivastava, A. Kumar, S. Kiruthika and G. U. Kulkarni, ACS. Appl. Mater. Interfaces., 2014, 6, 13688-13696.

40 G. Kim, L. Shao, K. Zhang and K. Pipe, Nat. Mater., 2013, 12, 719-723.

41 P. C. Hsu, X. G. Liu, C. Liu, X. Xie, H. R. Lee, A. J. Welch, T. Zhao and Y. Cui, Nano. Lett., 2015, 15, 365371.

42 P. Ilanchezhiyan, A. S. Zakirov, G. M. Kumar, S. U. Yuldashev, H. D. Cho, T. W. Kang and A. T. Mamadalimov, RSC. Adv., 2015, 5, 10697-10702.

43 T. J. Kang, T. Kim, S. M. Seo, Y. J. Park and Y. H. Kim, Carbon, 2011, 49, 1087-1093.

44 Y. H. Yoon, J. W. Song, D. Kim, J. Kim, J. K. Park, S. K. Oh and C. S. Han, Adv. Mater., 2007, 19, 4284-4287.

45 D. Jung, D. Kim, K. H. Lee, L. J. Overzet and G. S. Lee, Sensor. Actuat. A. Phys., 2013, 199, 176-180.

46 J. Yan and Y. G. Jeong, Sensor. Actuat. A. Phys., 2015, 86, $72-79$.

47 J. J. Bae, S. C. Lim, G. H. Han, Y. W. Jo, D. L. Doung, E. S. Kim, S. J. Chae, T. Q. Huy, N. V. Luan and Y. H. Lee, Adv. Funct. Mater., 2012, 22, 4819-4826.

48 K. Y. Shin, J. Y. Hong, S. Lee and J. Jang, J. Mater. Chem., 2012, 22, 23404-23410.

49 S. Maity, A. Chatterjee, B. Singh and A. P. Singh, J. Textile. Institute., 2014, 105, 887-893.

50 K. Opwis, D. Knittel and J. S. Gutmann, Synthetic Metals, 2012, 162, 1912-1918.

51 A. Laforgue, J. Material. Chem., 2010, 20, 8233-8235.

52 M. De Jong, L. Van IJzendoorn and M. de Voigt, Appl. Phys. Lett., 2000, 77, 2255.
53 S. Dupont, F. Novoa, E. Voroshazi and R. Dauskardt, $A d v$. Funct. Mater., 2014, 24, 1325-1332.

54 F. Wang, C. Gao, K. Kuklane and I. Holmer, Int. J. Occup. Saf. Ergon., 2010, 16, 387-404.

55 W. B. Lu, M. Zu, J. H. Byun, B. S. Kim and T. W. Chou, Adv. Mater., 2012, 24, 1805-1833.

56 H. Okuzaki and T. Kunugi, J. Polym. Sci. Pol. Phys., 1998, 36, 1591-1594.

57 M. M. Ma, L. Guo, D. G. Anderson and R. Langer, Science, 2013, 339, 186-189.

58 C. S. Haines, M. D. Lima, N. Li, G. M. Spinks, J. Foroughi, J. D. W. Madden, S. H. Kim, S. L. Fang, M. J. de Andrade, F. Goktepe, O. Goktepe, S. M. Mirvakili, S. Naficy, X. Lepro, J. Y. Oh, M. E. Kozlov, S. J. Kim, X. R. Xu, B. J. Swedlove, G. G. Wallace and R. H. Baughman, Science, 2014, 343, 868-872.

59 H. Okuzaki, T. Kuwabara, K. Funasaka and T. Saido, $A d v$. Funct. Mater., 2013, 23, 4400-4407. 


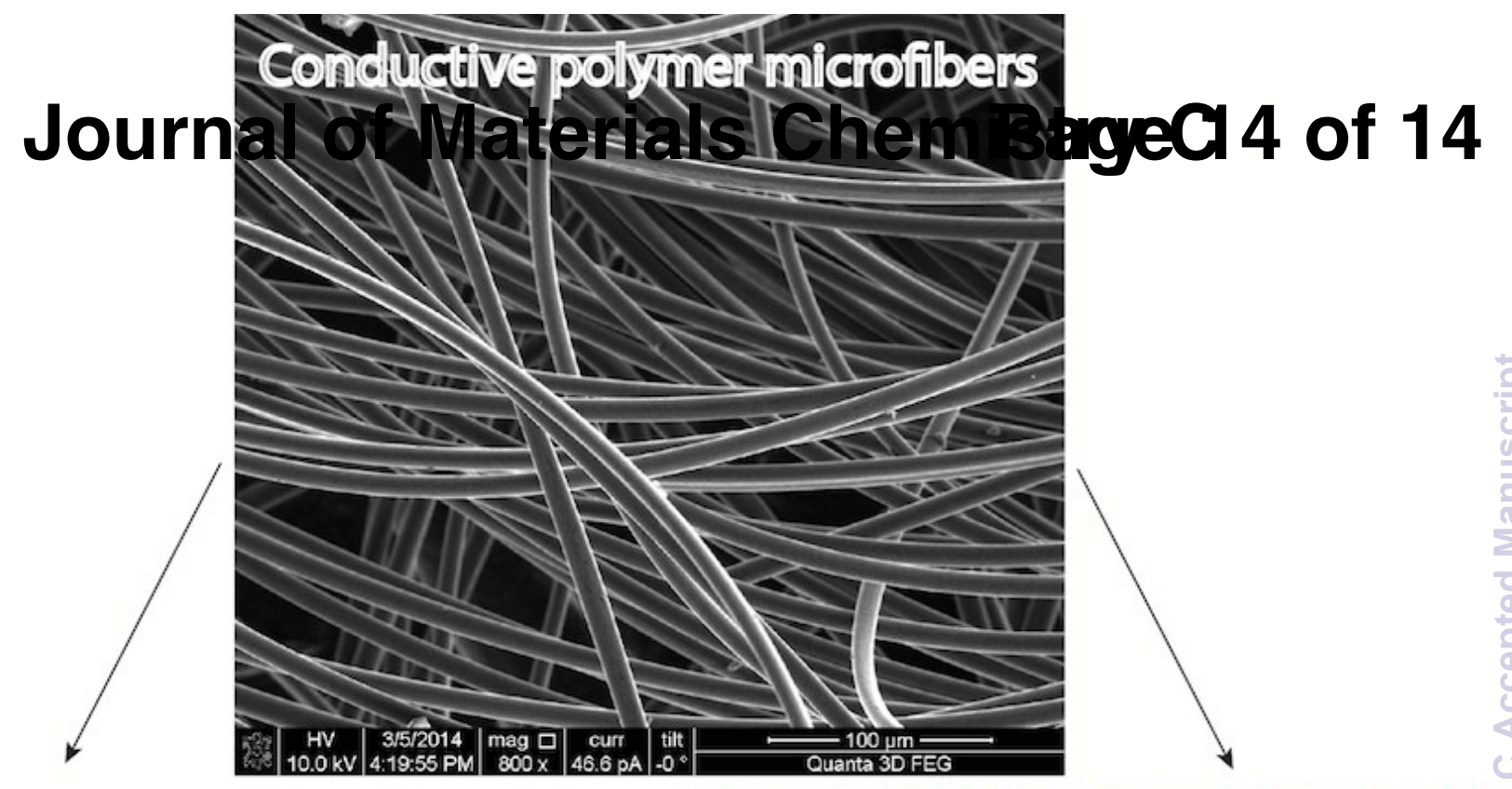

Heatable glove

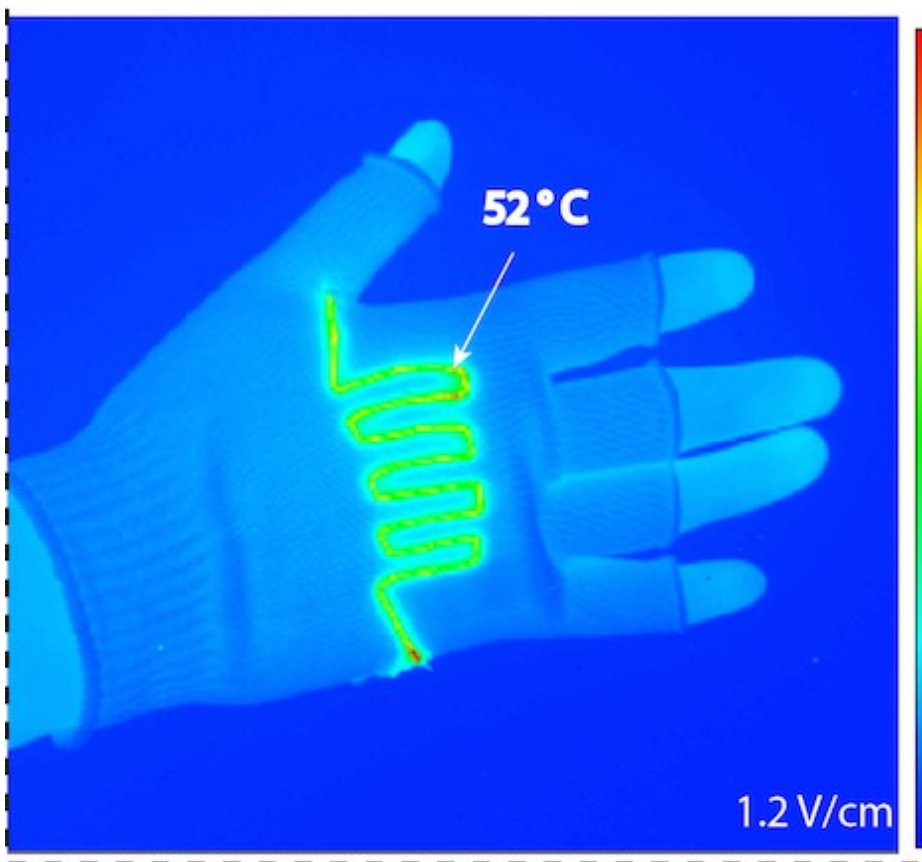

Linear actuator

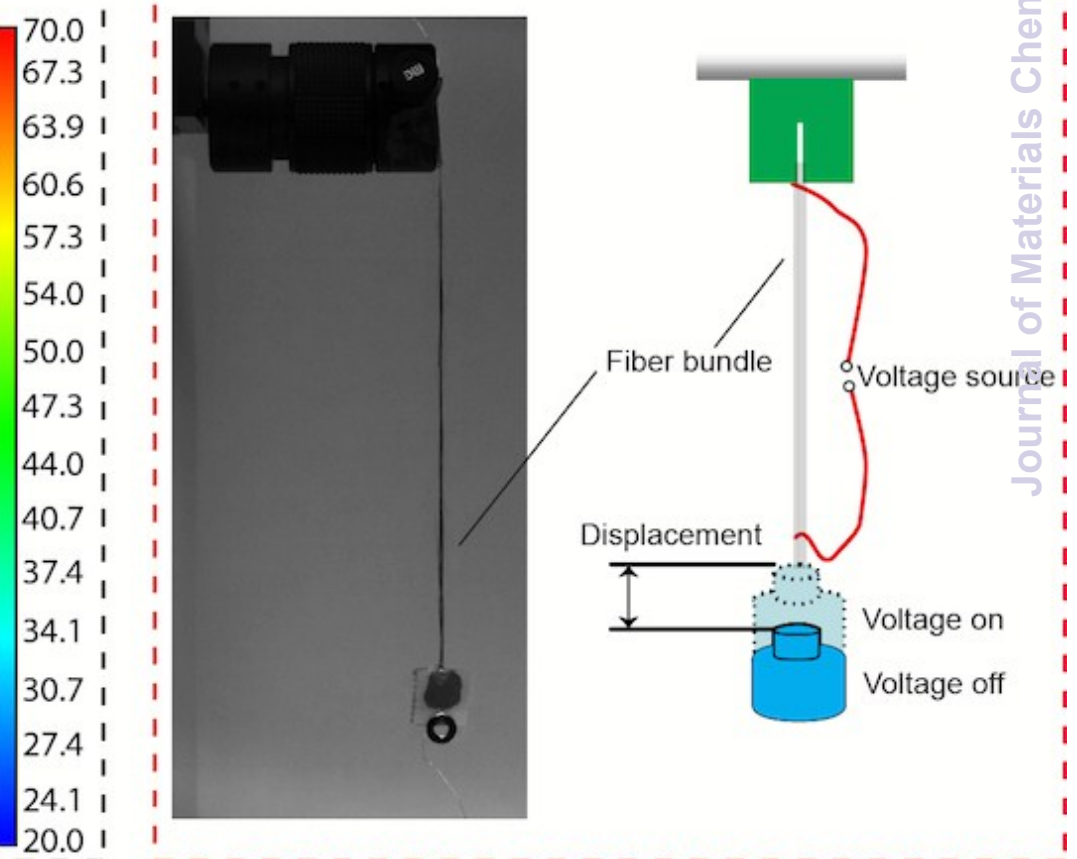

20.01 